\title{
Chapter 6 \\ Focus movement can be destressing, but it need not be*
}

\section{Kriszta Szendröi}

This paper has two parts. First, I investigate the possibility of focus movement inside the noun phrase, reanalysing some of the data I discussed in Szendröi (2010), reaching partially different conclusions. I follow Neeleman et al (2009) in treating focus movement as an instance of movement marking the domain of contrast. I propose that adjective reordering in English should be analysed in these terms. Some of the evidence for this analysis comes from the possibility of reconstruction in such cases. In contrast, the Greek polydefinite construction, which is often argued to involve DP-internal focus movement, does not mark the domain of contrast and does not involve movement. Rather, it seems to involve givenness marking (Lekakou and Szendröi 2012). This raises the theoretical question whether contrastive focus marking and givenness marking is two sides of the same coin, as suggested by Schwarzschild (1999) and more recently by Wagner $(2006,2010)$. The second part of the paper is devoted to this issue. I present some new theoretical and empirical arguments against this unified position, supporting earlier proposals along these lines by Neeleman and Reinhart (1998), Neeleman and Szendröi (2004), Féry and SamekLodovici (2006), Krifka (2006) and Reinhart (2006).

* This paper would have never taken shape without the perfect combination of gentle pressure and seemingly inexhaustible patience of the editors, Ad Neeleman and Reiko Vermeulen. I am very grateful to them. I also thank them for helpful suggestions and thorough discussions of the material. For suggestions, data, comments and discussions I am also indebted to Ingo Feldhausen, Berit Gehrke, Hans van de Koot, Timothy Leffel, Marika Lekakou and audiences of the Prosody colloquium at the University of Frankfurt (1 February 2012) and the graduate course on information structure at Potsdam University (20 February-2 March 2012). This paper includes material published in Szendröi (2010). Lingua's permission to reproduce this material is gratefully acknowedged here. 


\section{Introduction}

Szendröi (2010) reviewed a series of phenomena where it has been previously proposed that topic and focus movement takes place DP-internally, targeting designated left-peripheral high functional heads in the DP. I argued there that the DP, being argumental and not propositional, is illsuited for topic/comment or focus/background partitioning (see also Sánchez 2010:130-131 for the same claim not only for regular DP arguments but also for nominalised clauses lacking independent tense in Quechua). For this reason, no such partitioning can take place DP-internally. I looked at two sets of data in more detail: adjective reordering and polydefinites in Greek. ${ }^{1}$ For the former, I claimed, the reordering serves scope considerations; for the latter, I suggested that givenness rather than focussing was the correct trigger. In the light of recent proposals about focus movement in Neeleman et al (2009) and Wagner (2005, 2010), I would like to re-examine these data. I will conclude that focus movement marking its sister as its domain of contrast is possible inside the noun phrase. Arguably, this takes place in the case of noncanonical adjective placement. In the absence of movement, the domain of contrast is not explicitly marked in the syntax. This is the situation, I will argue, in the Greek polydefinite construction, whose function is to deaccent its nominal head and thus mark it as anaphorically given. Next, I will consider Wagner's $(2006,2010)$ proposal that focussing a constituent is the same thing as marking its sister as given and vice versa. I will argue that this 'see-saw' theory of focusing and givenness, although very attractive, cannot be the whole story: it must be supplemented by an independent stress strengthening (i.e. focussing) mechanism. The arguments presented fall in line with much previous work by Neeleman and Szendrői 2004, Féry and Samek-Lodovici (2006), Krifka (2006) and Reinhart (2006).

Many languages show discourse-related word order variation. It is generally accepted that examples like (1) involve a topic/ comment structure, while (2) involves a focus/ background structure.

(1) This tie, Fred bought.

(Cormack and Smith 2000:390)

(2) Nothing I ate for breakfast.

(Cormack and Smith 2000:397)

1 At the end of Szendrői (2010), I also reviewed claims about alleged topic movement inside the Hungarian DP involving dative possessors. I hope to have shown that there is nothing topical about them. I will not repeat the arguments here as this paper concentrates on focus movement. 
Reinhart (1981), following Strawson (1964), proposed that when an utterance is assessed in context, this process involves checking 'predication', where one expression in the sentence is taken as the argument and the rest as the predicate. The argument is the topic of the utterance in the given context; the predicate is the comment. Syntactic considerations may constrain what the topic (i.e. the argument of the predication) may be. For instance, in passives, the topic must be the subject and in clitic-left dislocation, the topic is always the dislocated element. In utterances like (1), the topic is distinguished by its position, the rest of the utterance constitutes the comment.

Focus is the part of an utterance that provides an answer to a corresponding (implicit) $w h$-question. This can be implemented with structured meanings (Jacobs 1983, Von Stechow 1990, Krifka 2006) as well as alternative semantics (Rooth 1992). Either way, what is important is that the background associated with the focus determines the set corresponding to the implicit $w h$-question. In other words, the background is an open proposition, which can be matched to a set of alternatives. In utterances like (2), the focus is syntactically displaced, and the background is the open proposition constituted by the rest of the utterance.

Neeleman et al (2009) propose an account based on the idea that A'movement of a contrastive topic or focus determines its scope, much like A'-movement of other quantificational elements. The movement marks what material is included in the scope of this operator, which they call the domain of contrast (DoC). The proposal is formalized as below.

DoC Marking

The sister of a moved contrastive focal (or topical) constituent, $\mathrm{XP}$, is interpreted as the domain of contrast for XP.

(adapted from Neeleman et al 2009 ex. 10)

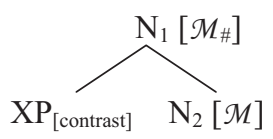

(Neeleman et al 2009 ex.11)

If a contrastive topic or focus remains in situ, the domain of contrast is not marked. In interpreting the sentence, the hearer must therefore construe an appropriate domain of contrast based on contextual clues. This can be the sister of the contrastive category, but it can also contain more material and as a result be discontinuous. In other words, the DoC for XP in (5) can be its sister, as in (5b) or YP minus XP itself, as in (5a). A'-movement of 
the contrastive category has a disambiguating effect, as it creates a match between the syntactic representation and the information structure associated with the sentence, as shown in (5b).

a.



b.

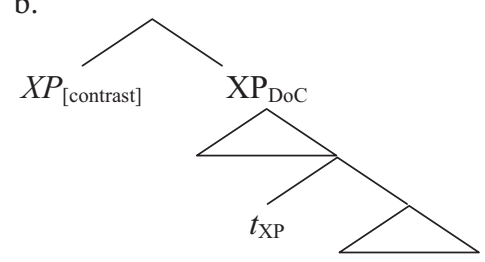

To illustrate, in (6), the contrastive focus XP FLOWERS has been fronted, marking its sister John has given $\mathrm{t}_{\mathrm{XP}}$ to Mary as the domain of contrast. The specific semantic representation Neeleman et al propose for (6) is given in (7), with the DoC underlined. In plain terms, in (6), flowers are contrasted with other entities that John could have given to Mary.

(6) FLOWERS John has given to Mary.

(7) a. $<\lambda x$ [John has given $x$ to Mary], flowers, \{flowers, chocolate,...\} $>$

b. $\exists y[y \in\{$ flowers, chocolate, ... $\} \& \neg[$ John has given $y$ to Mary $]]$.

Neeleman et al also discuss cases where the focal element does not move to the left-periphery, but to a position below the subject. This is not allowed in English, but Dutch, for instance, allows focus movement to target the so-called middle field of the sentence. The semantics they propose for such cases is given in (8). Here, the DoC is not an open proposition. When this is the case, they argue, existential closure applies to the DoC (underlined). This gives rise to a meaning where flowers are contrasted with other entities that someone could have given to Mary.
a. $\quad\langle\lambda x$ [John has given $x$ to Mary], flowers, \{flowers, chocolate, $\ldots\}\rangle$
b. $\exists y[y \in\{$ flowers, chocolate,..$\} \& \exists z \neg[z$ has given $y$ to Mary $]]$.

This solution follows Schwarzschild (1999)'s proposal. Wagner (2010) argues for a somewhat different solution involving universal closure. The technical details of the solution need not concern us here. What matters is that the DoC may be semantically something other than an open proposition, and by closure, an open proposition can be obtained. This paves the way for a treatment of DoC-marking DP-internally. In particular, what 
Neeleman et al argue is that the material that is not part of the domain of contrast is simply filled in from the context. So, in (8), the giving event will be understood to involve John as its subject if John is the most easily accessible individual in the previous context. Similarly, if domain of context marking takes place inside the DP argument, the predicate and the remaining arguments will be represented by existentially bound variables and specified further by the preceding context.

Wagner $(2006,2010)$ looked at cases involving noncanonical stress placement inside the DP, such as (9) and (10). He argued that destressing the noun convertible is only possible if it is contextually given and its sister constituent, the adjectival modifier, can be felicitously contrasted with the modifier of the antecedent. So, (9b) is inappropriate because blue does not contrast with high-end, while (10b) is well-formed because cheap does.

(9) Sally's uncle, who is incredibly rich and produces high-end convertibles, came to her wedding. I wonder what he brought as a present.

a. Guess what: He brought a blue CONVERTIBLE.

b. ?\# Guess what: He brought a BLUE convertible.

(Wagner 2010:13 ex 21)

(10) Sally's uncle, who is incredibly rich and produces high-end convertibles, came to her wedding. I wonder what he brought as a present.

a. ?\# Guess what: He brought a cheap CONVERTIBLE.

b. Guess what: He brought a CHEAP convertible.

(Wagner 2010:13-4 ex 22)

Based on examples like these, he argued for what I will call the 'see-saw' theory of focus and givenness. He follows Williams (1997) in assuming that accent placement can be represented by assigning Strong or Weak labels to binary branching sisters. Marked accent placement is the result of a Strong-Weak swap on a pair of sisters. In particular, Wagner claims, assigning Weak to the noun convertible, by virtue of it being given in the preceding discourse, automatically means assigning Strong to its sister node, the adjectival modifier. As a direct consequence of this, the adjective will be interpreted contrastively (invoking a set of alternatives). Thus, it is only if the arising contrast is meaningful (i.e. cheap vs. highend but not blue vs. high-end) that destressing on the noun can take place. I will come back to a more thorough discussion of this proposal in section 3.

Recall that Neeleman et al (2009) argue that the sister of a moved focal element is marked as its domain of contrast. Thus, focus movement is 
scope-driven movement. Wagner $(2006,2010)$ argued that givenness marking and focus marking are two sides of the same coin. Although he does not discuss cases of movement, a straight forward extension of his proposal would mean that focus movement involves assigning a Strong label to the moved constituent, and by the see-saw, assigning Weak to its sister node, as given schematically in (11).

$$
\begin{aligned}
& \text { Extension of Wagner (2010) to focus movement: } \\
& {\left[\begin{array}{lll}
\mathrm{XP}_{\text {Strong }}[\text { Weak } & \cdots & \left.\mathrm{t}_{\mathrm{XP}} \ldots\right]
\end{array}\right]}
\end{aligned}
$$

In principle, it is possible that both Neeleman et al (2009) and Wagner $(2006,2010)$ are correct and the moved constituent marks its sister as the domain of contrast and given at the same time. Indeed, this will hold in many cases. Contrastive focus is often used in discourse situations where the domain of contrast is given. Take for instance an instance of correction, as in (12).
A: She took the $\mathrm{S} 7$ to Wannsee.
B: No. The S1 she took.

However, this does not mean that this always holds, or that it must hold. In what follows I will look at a series of data where the two theories potentially diverge.

\section{Adjective reordering inside DP: A-bar movement marking the domain of contrast}

\subsection{Adjective reordering marks the domain of contrast}

The evidence presented in favour of a DP-internal topic or focus position in the literature involves several different lines of argumentation. I will start by looking at what I believe is the most robust set of data: adjective reordering associated with contrastive focus. In the next section, I will turn to the Greek polydefinite construction, which has been argued to involve DP-internal focus movement in many proposals (see e.g. Ntelitheos 2004, Kariaeva 2004, Ioannidou and Den Dikken 2009).

Truswell (2005) is concerned with certain discourse-related word order variations inside the DP. (See also Laenzlinger $(2000,2005)$ ). He admits that a syntactic parallel between the clausal left-periphery and the DP is 
less than straight forward, but nevertheless claims that data like (12) give evidence for focus movement inside the DP. ${ }^{2}$

$$
\text { My friends all drive big cars, but only I drive a BLACK big car. }
$$

(Truswell 2005)

Here the normal ordering between a subsective adjective like big and an intersective adjective like black is reversed and the intersective adjective bears heavy, contrastive stress and pitch accent. Truswell notes that such reordering is only possible if the intersective adjective is contrasted. He thus concludes that the adjective is fronted inside the DP in order to be marked for contrastive focus.

But note that reordering is not necessary for a contrastive focus reading. In (14) the adjectives follow the normal order and the contrasting intersective adjective is only marked prosodically. So, focus movement inside the DP, if this is what this example contains, is optional.

$$
\text { My friends all drive big cars, but only I drive a big BLACK car. }
$$

To see what the real import of the noncanonical adjective ordering is, consider an utterance like (15), which is a simplified version of (13). By Neeleman et al's proposal, the domain of contrast is the NP big car, which is the sister of the accented adjective $B L A C K$. So, (15) is appropriate in the discourse context 1, given in (16a) (also illustrated by Scenario 1). In this context there is a given set of big cars (known to the speaker and the hearer) one of which is black. But the same utterance is not felicitous in discourse context 2 (illustrated in Scenario 2), where there is a set of black cars one of which is big alongside other sets of cars of different colours where one of each set is big.

I drive a BLACK big car. Context 1: $\checkmark \quad$ Context 2: \#

(16) a. Context 1: In this car park you can see my friends' cars and my car. There is a bunch of big cars here. They are of many different colours.

Scenario 1: BLACK RED BLUE WHITE BLUE YELLOW

2 Note that Truswell (2009) concludes that adjective reordering is often scopally motivated, rather than information structurally. Similar data is discussed below (cf. the collective reading of (22)). 
b. Context 2: In this car park you can see my friends' cars and my car. There are cars of many different colours. Some of them are small, but there are big cars of every colour.

Scenario 2: black BLACK black black

red red red $R E D$ red red $\cdots$

So, the import of noncanonical adjective placement seems to be marking the modified noun, big car in our example, as the domain of contrast. The adjective $B L A C K$ is contrastively focussed. But it is not focusing the adjective that distinguishes this order from the canonical order, but marking the modified noun big car as the domain of contrast.

As expected, the canonical order, given in (17), is compatible with either scenarios in (16). This is because this utterance contains canonical order and stress shift to the adjective $B L A C K$. The latter operation has the effect of focusing the adjective and also, by the see-saw, marking its sister, the noun car, as given. This is compatible with Context 2. In addition, (17) is also appropriate in Context 1 , where the domain of contrast is determined by the modified NP big car. But since no focus movement took place, the domain of contrast need not directly correspond to a syntactic constituent. It can be discontinuous. Hence the appropriateness of (17) in Context 1 follows.

$$
\text { I drive a big BLACK car. Context } 1: \checkmark \quad \text { Context } 2: \checkmark
$$

The following example shows that contrast on the moved adjective is necessary. If the adjective black is not contrastive, it cannot appear in a noncanonical position. ${ }^{3}$

*All my friends drive a black car and I drive a black BIG car.

To sum up, the domain of contrast for the noncanonically placed focused adjective is its sister. What licences the noncanonical placement is that this allows for marking the modified noun phrase big car to be the domain of contrast.

3 This needs to be qualified in the light of scope data discussed below. There we will see that the adjective can also appear in a noncanonical position if that expresses a special scope reading. 


\subsection{Adjective reordering involves A-bar movement}

Next we should establish whether noncanonical adjective placement involves movement or just a noncanonical base-generated order. To see this, we have to briefly examine how focus movement interacts with scope in the clausal domain.

As Neeleman \& van de Koot (2007) demonstrate, languages like Dutch allow two different types of scrambling. So-called A-scrambling, interacts with A-binding and secondary predication, does not give rise to weak crossover effects and never reconstructs for scope. In contrast, A-bar scrambling, does not affect binding or secondary predication, gives rise to weak crossover effects and obligatorily reconstructs for scope. The two also have distinct discourse properties: A-scrambling affects discourse anaphoric elements; elements that undergo A-bar scrambling are either (contrastive) topics or foci. These opposing sets of properties led Neeleman \& van de Koot (2007) to offer different syntactic analyses for the two different types of scrambling. They claim that A-scrambling is the result of different base-generated orders (see also Ruys 2001), while A-bar scrambling is essentially topic or focus movement, triggered by the aim to create a syntactically continuous comment or background.

Since here we are interested in the different scopal properties of the two constructions, I give the relevant data in (19) and (20). (See Neeleman \& van de Koot (2007) and references there for the rest of the data.) As (19) shows, an indefinite noun phrase that has been A-scrambled across an adverb cannot reconstruct for scope under the adverb.

a. dat ik waarschijnlijk iemand uit New York zal uitnodigen that I probably someone from New York will invite (i) ?someone > probably; (ii) probably > someone 'that I will probably invite someone from New York'

b. dat ik iemand uit New York waarschijnlijk zal uitnodigen that I someone from New York probably will invite (i) someone > probably; (ii) * probably > someone 'that I will probably invite someone from New York'

In contrast, as (20) shows, A-bar scrambling allows for reconstruction. Here the reading where 'most' outscopes 'at least one' is available. ${ }^{4}$

4 In fact, Neeleman \& van de Koot (2007) present arguments that in sentences in which focus movement spans a clause boundary, reconstruction is obligatory but this need not concern us here. 
dat [ tenminste ÉÉN artikel over syntaxis] de meeste studenten $t_{\mathrm{DP}}$ wel that at-least one article about syntax the most students indeed gelezen zullen hebben read will have

(i) at least one > most; (ii) most > at least one

'that most students will at least have read one article about syntax'

The syntactic analysis proposed by Neeleman \& van de Koot (2007) captures the scope reconstruction data in a straightforward manner:A-scrambling is analysed as a different base-generated order, so it is not surprising that it does not allow reconstruction; A-bar scrambling, which involves A-bar movement, unsurprisingly, allows reconstruction for scope.

Now the question is whether the adjective reordering data patterns with A-scrambling or with A-bar scrambling with respect to scope reconstruction (the other tests Neeleman \& van de Koot (2007) enumerate are not replicable in the DP domain). Going back now to our constructed scenarios in (16), the inappropriateness of the example with noncanonical adjective order (15) in the Context 2, where cars of no particular size (or colour) were mentioned shows that the adjective does not reconstruct for scope. As argued above, lack of reconstruction is the property associated with A-scrambling and in turn with different base-generated orders. At first blush, this suggests that (15) (and also (13)) does not involve DPinternal adjective movement. Rather, such utterances have an atypical base-generated adjective sequence. In the noncanonical order, the order of the adjectives reflects their scopes. Unfortunately, however, this reasoning is faulty. The point is that in my proposal, which follows Neeleman et al's (2009) proposal, the function of the noncanonical adjective placement is to allow for the domain of contrast to be marked syntactically as the modified NP big car. So, why should the adjective scopally reconstruct to a smaller domain of contrast (i.e. car)? If movement is to mark DoC explicitily, it is not going to reconstruct for DoC even if noncanonical adjective placement is indeed the result of A-bar movement. In order to test for reconstruction we need to look at examples that mark scope in different ways.

One such example is (21). As Scott $(2002: 113)$ notes, the utterance may be uttered in a context where it has been established that Carol has twelve children, six of them horrible and another six, nice. He takes this to be indicative of focus movement inside the DP. In our terms, the noncanonical adjective placement would be marking the numeral-noun complex six children as the domain of contrast. 
Carol's horrible six children made life miserable for her second husband.

(Andrews 1983:697)

But this utterance is also perfectly felicitous in a context where Carol has six children altogether, all of them horrible. The noncanonical adjective placement is then licensed by the quantificational reason that it is the group of six children rather than their cardinality that is horrible' (Andrews 1983:697, cited in Scott 2002:113). Note that under this collective reading the adjective horrible need not even be stressed:

Carol has six children.

a. As a group, her horrible six children make life miserable for her second husband.

b. \#Her horrible six children each make life miserable for her second husband.

It is now possible to construct an example where two kinds of quantificational considerations can be combined: the domain of contrast and the collective reading. In (23), the context indicates that the domain of contrast for the adjective horrible is the NP six children. As (23a) and (23b) show the domain of contrast can be explicitly marked in syntax by the noncanonical placement of the adjective HORRIBLE. The relevant example is (23b), as it shows, that this time, the distributive reading is available, indicating that the adjective can reconstruct for scope under the numeral.

Context: Carol has 12 children, 6 horrid, 6 kind. $\quad$ (DoC: six children)

a. As a group, her HORRIBLE six children make life miserable for her second husband. collective reading: $\checkmark$

b. Her HORRIBLE six children each make life miserable for her second husband. distribuitive reading: $\checkmark$

Note that it is not entirely obvious that (23) is completely parallel to an example with adjective reordering as (15). It is possible that when an adjective appears in front of a numeral it moves from a lower position, while it is simply base-generated in a higher position when it scopes over another adjective. So, we need to consider such cases separately.

Arguably, such a case can be constructed involving adjectives as in (24). (24a) is a pragmatically unnatural order, as its reading suggests that the chicken in question was first frozen and then sliced. In contrast (24b) sim- 
ply means sliced chicken with a temperature below zero. (24c) is ok with a contrastive reading, as indicated. Nevertheless, it need not mean the pragmatically odd reading that would require a chainsaw. Rather, it seems possible to contrast (24c) under the natural reading also examplified in (24b).

a. \#some sliced frozen chicken reading: sliced $>$ frozen

b. some frozen sliced chicken reading: frozen $>$ sliced

c. some SLICED frozen chicken (not, say, some MINCED frozen chicken) reading: sliced $>$ frozen: $\checkmark$ frozen $>$ sliced: $\checkmark$

A further case has been cited by Scott $(2002: 113)$. He noted that examples like (25a) and (25b) have distinct scopal orders. (25a) involves noncanonical adjective ordering. To the extent that this adjective placement not only marks the domain of contrast, but also determines the scope of alleged, there seems to be no reconstruction, as (24a) does not seem allow a reading where the person was not simply an alleged baron but an alleged English baron. But judgments here are very subtle.

a. an ENGLISH alleged baron

b. an alleged ENGLisH baron

A more transparent case was suggested to me by Ad Neeleman and Reiko Vermeulen (p.c.). In the context provided, the utterance in (26) is wellformed. Given this context, it must refer to British passports in the sense of documents that can prove British citizenship. This is because the context actually specifies that the documents in question were made in the DDR, so they could be referred to as German fake British passports. So, the adjective British can occupy a noncanonical position, marking the NP fake passports as its domain of contrast, while it reconstructs for scope under the adjective fake. ${ }^{5}$

5 In fact, one native speaker that I have consulted marginally accepted BRITISH German fake passports in the above context. But in a revised context where fake passports of various nationalities made in different countries of the former Eastern Block, i.e. Czech fake British passports, Czech fake French passports, ... East German fake British passports, East German fake French passports, ..., are available, she preferred the order GERMAN BRITISH fake passports to refer to fake British passports made in the DDR. This is in accordance with the proposal. In this revised context country of origin is no longer 
Context:We're in a museum looking at a series of fake passports produced by the East German secret service in the 1970s. There are fake passports from many countries: fake French passports, fake Dutch passports, fake British passports, and so on. You turn to guide and say: I have a question about the BRITISH fake passports

To conclude this section, my claim is that adjective reordering is triggered by scope requirements: the need to mark the post adjectival constituent as the domain of contrast for the adjective. The operation, in line with other A-bar movement operations (see Bobaljik and Wurmbrand 2010 for a similar claim), allows reconstruction. Although it is possible to account for this by assuming a DP-internal designated functional FocusP inside DP, this would not adequately express the fact that the position of the fronted adjective does not seem to be predetermined by a specific focus position in the cartographic sense, i.e. in the sense that the position would always be preceded and followed by the same functional heads. Rather, as the interpretative effect of the reordering is not focus on the fronted adjective, but rather scope, marking the domain of contrast, the target position is variable depending on the size of the domain of contrast: it can involve other adjectives or the numeral.

\section{The Greek polydefinite construction: givenness marking}

\subsection{No A-bar movement, no domain of contrast marking}

Having shown that adjective reordering in English involves DP-internal A-bar movement marking the domain of contrast for the contrastively focused adjective, I will now proceed to analyse the so-called polydefinite construction in Greek. I will argue against analyses that treat this as an instance of DP-internal focus movement (e.g. Ntelitheos 2004). Instead, I will argue that the function of the construction is givenness marking. In particular, I will propose that the syntax (and semantics), proposed by Lekakou and Szendroi (2012), coupled with Wagner's $(2006,2010)$ account of givenness, captures the data. Thus, under the present proposal, the construction does not involve A-bar movement and consequently no domain of contrast marking in the sense of Neeleman et al (2009).

part of the domain of contrast, but rather a point of contrast itself, as there are passports from many different countries in this context. So, placement of BRITISH above German is not justified. 


\subsection{The syntax of the Greek polydefinite construction}

The Greek polydefinite is a combination of at least one adjective and a noun where each features its own determiner, as in (27).

a. to megalo to spiti the big the house

b. to spiti to megalo the house the big 'the big house'

Polydefinites co-exist in the language with monadics like (28), i.e. modification structures where only one determiner is present-although polydefinites have special syntactic, semantic and pragmatic properties (see Kolliakou (2004) and Campos and Stavrou (2004)).
a. to megalo spiti the big house
b. *to spiti megalo the house big 'the big house'

Ntelitheos (2004) argued that the polydefinite construction involves DPinternal focus movement (see also Ioannidou and Den Dikken (2009) for a similar claim). Following Kolliakou (2004), I will try to show that a better interpretation of the data is that it relies on givenness, not focus. Focus only arises by the prosodic see-saw of Wagner (2010). Following Lekakou and Szendrői (2012), I will present a syntactic analysis of the construction where the different orders are due to base-generation, rather than movement. But let us review Ntelitheos' proposal first.

Ntelitheos (2004) proposes an analysis that treats discontinuous DPs, NP-ellipsis and polydefinites in a parallel structure. In Greek, the fronted part of a discontinous NP is focused:

$$
\begin{aligned}
& \text { to kokkino idha to forema. } \\
& \text { the red saw-1S the dress } \\
& \text { 'It is the red dress that I saw.' }
\end{aligned}
$$

In addition, the second part can easily undergo NP-ellipsis, even if the first part remains in situ. 
to KOKKINO idha.

the red saw-1S the dress

'It is the red one that I saw.'

Moreover, the first part of the DP need not move, giving rise to what is called the polydefinite construction (Kolliakou 2004):

idha to kokkino to forema.

saw-1S the red the dress

'It is the red dress that I saw.'

Ntelitheos $(2004: 10)$ proposes that all three rely on a common structure, which involves focus movement inside the DP, with the fronted part moving to a DP-internal FocusP, and the elided part moving into a DP-internal TopicP. This is the analysis of the polydefinite in (31). In the NP-ellipsis case in (30), the TopicP inside the DP undergoes deletion. In the discontinuous DP case in (29) the DP-internal FocusP undergoes further movement to the clausal FocusP.

Although potentially far-reaching, this unified treatment of the data is undermined by the following problem. There are languages that allow discontinuous NP-topicalisation and NP-ellipsis, but where DP-internal focus fronting is not possible. This is unexpected in a theory where both these constructions rely on the availability of DP-internal focus fronting. Take Hungarian. In (32a) we see a case of discontinuous DP-topicalisation ${ }^{6}$; (32b) illustrates NP-ellipsis. (32c) and (32d) illustrate that focus movement inside the DP is impossible, with (32c) involving movement of the $\mathrm{N}$ over the $\mathrm{A}$, and (32d) involving movement of the A over a possessor. (The brackets around the accusative markers indicate that the problem with these examples is not due to the presence of double accusative marking.)

a. Bicikliket, a nagyokat vettem.

bikes-acc the big-pl-acc bought-I

'Bikes, I bought the big ones.'

6 In (32a) the adjectival part of the discontinous DP is in the focus position, while the nominal part is in a contrastive topic position. The parallel with the Greek data would be neater if the nominal part was in situ, but Hungarian does not allow B-accented contrastive topics to remain in situ and it seems that the nominal part of discontinuous DPs must be contrastive topics in this language. 
b. A nagyokat vettem. the big-pl-acc bought-I 'I bought the big ones.'

c. $*{ }_{D P}$ A biciklik(et) nagyok $\left.(a t) t_{N}\right]$ vettem meg. the bikes-acc big-pl-acc bought-I prt 'I bought the big bikes.'

d. * ${ }_{D P}$ A nagy(okat) Péternek $\mathrm{t}_{\mathrm{A}}$ bicikliei( $\left.\left.\mathrm{t}\right)\right]$ vettem meg. the big-pl-acc Peter-dat bikes-poss3sg-pl-acc bought-I prt 'I bought Peter's big bikes.'

It is of course possible to analyse NP-ellipsis and discontinuous NP fronting in ways that do not rely on the availability of DP-internal focus fronting. But the Hungarian data suggests that the merits of Ntelitheos' proposal must be evaluated only with respect to the polydefinite construction. So, the analysis boils down to the question whether or not this construction involves DP-internal focus fronting. If this turned out to be the correct analysis of the data, that would constitute an argument in favour of the cartographic approach. In contrast, if it turned out that polydefinites can be reduced to NP-ellipsis, which as the Hungarian data shows is needed independently, that would make DP-internal focus movement superfluous. In what follows, I will demonstrate that this line of thinking is feasible.

Lekakou and Szendröi (2012) treat polydefinites as a case of close apposition, as in (33) from Greek and (34) from English:
a. o aetos to puli
the eagle the bird
b. to puli o aetos
the bird the eagle
'the eagle the bird (not the symbol)'
a. Burns the poet
b. the poet Burns

Since in close apposition both nominal parts contribute to the determination of reference, Lekakou and Szendröi (2012) suggest that both DPs involved in the construction are referential DPs. This is taken to mean that both DPs have an R(eferential) role in the sense of Williams $(1981,1989)$, Higginbotham (1985), Zwarts (1992), Baker (2003). In Williams' system, which is adopted by Lekakou and Szendröi, when a nominal occupies an argument position, its R-role is bound by a thematic role of the selecting 
predicate, whereas when the nominal occurs as a predicate, it assigns the R-role to its subject. Lekakou and Szendröi (2012) propose that in close apposition an operation takes place which identifies the R-roles of two DPs. This operation, which can be thought of as complex argument formation, is schematically illustrated in (35):



Applied to close appositives, theta-identification amounts to identification of two R-roles. This creates a syntactically symmetric structure: ${ }^{7}$

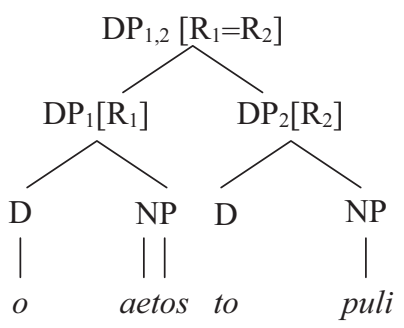

That close appositives involve a symmetrical syntactic structure is strongly suggested by agreement facts. An adjective in predicative position can agree in gender with either DP (provided of course that it can sensibly apply to either DP), as shown, in (37).
a. o aetos to puli ine megaloprepos/megaloprepo. the.m eagle $(\mathrm{m})$ the.n bird(n) is majestic.m/ majestic.n

b. to puli o aetos ine megaloprepos/megaloprepo the.n bird(n) the.m eagle $(m)$ is majestic.m/ majestic.n 'The eagle the bird is majestic.'

As far as polydefinites are concerned, Lekakou and Szendröi's (2012) proposal is that polydefinites are an instance of close apposition. They are

7 R-role identification solves a potential theta-theoretic problem that arises by assuming the availability of multiple R-roles within a CA: the occurrence of two (potentially) argumental DPs in the presence of a single theta-role assigner should violate the Theta Criterion. The actual mechanism is more complex than suggested in the text here. The reader is referred to Lekakou and Szendröi (2012) for details. 
only special in that they involve NP-ellipsis in one of their DP-subparts (cf. Panagiotidis (2005)):
a. $\left[_{D P}[D P\right.$
to
spiti] $[D$
house
to
megalo $\varnothing]]$
b. $\left[_{\mathrm{DP}}\left[\mathrm{DP}_{\mathrm{DP}}\right.\right.$ to
megalo $\varnothing \quad[$ DP
'the big house'

bi
to spiti]]
the house

The symmetric structure proposed for polydefinites/close appositives is perfectly consistent with their ordering freedom: Since the proposed structure is multiheaded, i.e. the two DPs are sisters, they can appear in either order. This explains the word order freedom exhibited by the construction. The presence of the multiple determiners is also accounted for, as in this analysis each heads its own DP projection. See Lekakou and Szendröi (2012) for more details.

Although there is some disagreement over whether the noun may bear stress at least in some orders (see Kariaeva 2004) most authors agree that the noun is usually destressed. The adjectives, in contrast, bear stress:

$$
\begin{aligned}
& \text { a. [ [ [weak to spiti] } \\
& \text { the house }
\end{aligned} \begin{array}{r}
[\text { Strong to megalo } \varnothing]] \\
\text { the big }
\end{array}
$$

3.3 The discourse role of the Greek polydefinite construction: givenness marking on the noun

Kolliakou (2004), who studied the Greek polydefinite construction in detail, claims that the pragmatic difference between the monadic construction and its polydefinite counterpart is not focusing the adjective, but deaccenting the noun. If this turned out to be correct, that would undermine a DP-internal focus movement analysis in a fundamental way. She proposed the data in (40) as characteristic of the discourse context in which polydefinites may occur. As (40d) shows, the polydefinite is licensed if the noun pena 'pen' is accessibly given information. Deaccenting the noun in the monadic construction, as in (40d'), is also possible in this context. 


\author{
a. Zoe: Ti pires tu Yanni gia ta christugena ? \\ 'What did you get Yiannis for Christmas?' \\ b. Daphne: (Tu pira) tin asimenia PENA. \\ (I got him) the silver pen. \\ b'. Daphne: \#(Tu pira) tin Asimenia pena. \\ \#(I got him) the silver pen. \\ b". Daphne: \#(Tu pira) tin pena tin asimenia. \\ I bought the pen the silver \\ \#(I got him) the silver the pen \\ c. Zoe: Ti pires tis Marias? \\ 'What did you get Maria?' \\ d. Daphne: (Tis pira) tin pena ti CHRISI. \\ (I bought her) the golden the pen \\ 'I got her the golden pen.' \\ d'. Daphne: (Tis pira) ti chrisi pena. \\ (I got her) the golden pen. \\ d" Daphne: \#(Tis pira) ti chrisi PENA. \\ \#'(I got her) the golden pen.
}

Note, however, that the above data can be interpreted in another way. One could argue that what licenses stress shift in (40d') and the polydefinite in (40d) is not the givenness of the noun, but rather the contrast on the adjective chrisi 'golden' with the previously mentioned adjective asimenia 'silver'. In this case, it would be focus, rather than givenness that licences the marked constructions. In Wagner's theory, the two analyses are actually indistinguishable: deaccenting the noun is only possible if the adjective can bear focus.

Lekakou and Szendröi (2012) argued that the adjectival part of a polydefinite is in fact a full DP involving NP ellipsis. It is well-known that there is a disanaphora requirement on the remnant of ellipsis. So, there are two possibilities: the polydefinite is licensed by focus on the elliptical DP; or the pragmatic function of the construction is destressing the DP containing the overt noun. In this latter case, the focal stress on the adjective is the direct consequence of Wagner's see-saw: the sister of a destressed constituent bears stress, and thus, focus. Being an elliptical DP, it will always be focusable. The following set of data attempts to show that even though the adjectival part of a polydefinite is focal, the polydefinite is not licensed unless the nominal part is given. 
The relevant set of data can be constructed using unexpected contrastive stress in contexts where there is no corresponding given constituent, such as Rooth's (1992) example in (41).

An American farmer was talking to a CANADIAn farmer. (Rooth 1992)

Féry and Samek-Lodovici (2006) argue that even if givenness can account for the deaccenting of the noun and the stressing of the adjective in the DP a Canadian farmer, it is impossible that stress on the adjective in the first DP, an American farmer, can be justified by the givenness of the noun. Rather, it must be the contrastive focus on the adjective that makes stress shift necessary. Although, Wagner (2010) argues against this conclusion and claims that examples like (41) involve cataphora. In other words, the first instance of the noun farmer is destressed in anticipation of the identical second occurrence of the same noun later. But the Greek data presented below argues against this conclusion.

In (42), which is based on Rooth's (1992) example, the contrast between the adjectives does not license the polydefinite. The fact that such cases can only be expressed by stress shift within the nominal in a monadic construction and not by the polydefinite, supports the idea that the polydefinite is licensed by givenness of the nominal part, rather than by focussing the adjectival part.

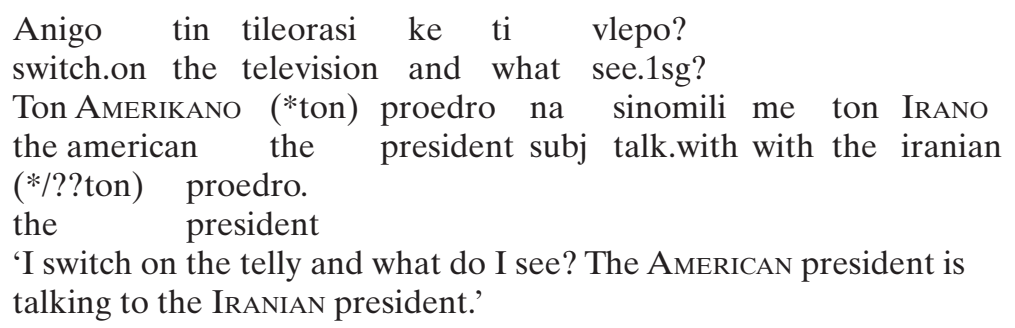

A similar datum can be constructed based on Krifka's (2006) example. In (43), the noun aftokinito 'car' is not given, and consequently the polydefinite is not allowed. The contrast between the adjectives (kokkino 'red' vs. ble 'blue') is not in itself enough to license the construction.

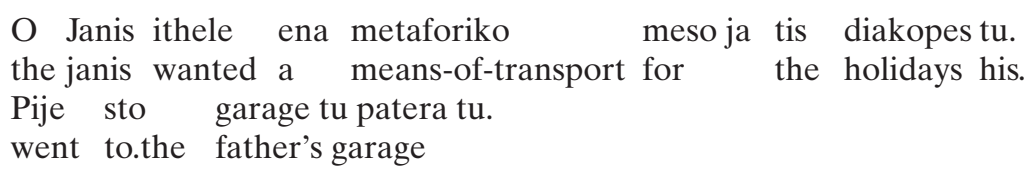




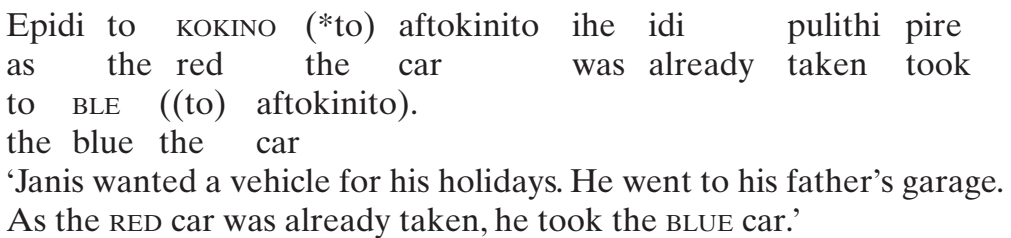

We can conclude that although there is a clear effect of focus on the adjectival part of the polydefinite, this is due to the fact that the construction involves NP-ellipsis, rather than DP-internal focus fronting. In carefully constructed examples where the nominal part is not given even though the adjectival part is contrastively focused, the polydefinite cannot be used. So, as Kolliakou (2004) argued, the pragmatic import of the polydefinite seems to be the deaccentuation and therefore givenness marking of the nominal part, rather than the focussing of the adjectival part.

A further argument in favour of a givenness approach as opposed to an approach based on focusing I would like to mention that even though data about different orders and especially about the relative pragmatic import of the different orders is notoriously subtle it seems to be the case that most authors agree that the noun is destressed in most orders (although see Kariaeva 2004). This can be nicely accommodated in the syntactic system proposed by Lekakou and Szendröi (2012) as they argue that the subparts of the polydefinite are appositive DPs. Based on a symmetric structure, it is understandable that the Strong and Weak labels can be assigned in any order, given that Weak-Strong ordering often reflects head-complement status (see Wagner 2006, 2010).

\subsection{No domain of contrast marking in the polydefinite}

The proposal here is that Neeleman et al's (2009) A-bar movement marking the domain of contrast can also apply in the DP domain. However, contrary to many analyses (e.g. Ntelitheos 2004), I do not think the Greek polydefinite construction involves DP-internal focus movement. Rather, its function is to mark its nominal component as given. If this is the case, then we do not expect that the construction marks the domain of contrast of the focal adjective. This seems to be on the right track.

Kyriakaki (2010:5-6) argues that the adjectival part bears focus in the DADN order but that this can be new information focus and need not be contrastive. 


$\begin{array}{llll}\text { Xriazome [TO } & \text { KOKKINO } & \text { to } & \begin{array}{c}\text { forema]. } \\ \text { (Kyriakaki 2010:6 ex 13) } \\ \text { dress-NEU }\end{array} \\ \begin{array}{l}\text { Need-1SG the-NEU } \\ \text { 'I need the RED dress.' }\end{array} & \text { thed-NEU }\end{array}$

In contrast, the a contrastive focus reading is the only one available if the polydefinite undergoes split with the adjectival DA-part fronted to the clausal focus position: ${ }^{8}$

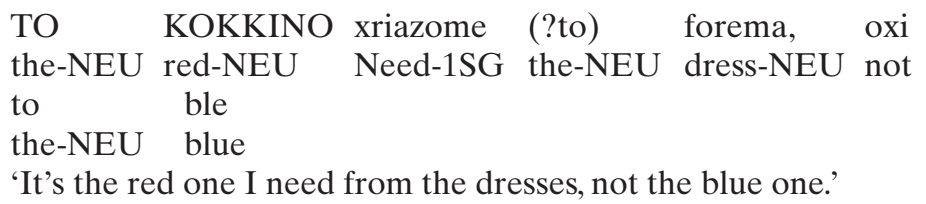

(Marika Lekakou p.c.)

This is in line with the analysis proposed here: focus movement is associated with domain of contrast marking (Neeleman et al 2009). Without the clausal split, the polydefinite simply marks the noun as given, and by the see-saw the adjectival part as focused. But contrast is not necessarily available and the domain of contrast is not explicitly marked syntactically unless the polydefinite undergoes DP-split with the adjectival DA-part fronted to the clausal focus position.

The case of the Greek polydefinite construction highlights the need to distinguish form and function. Because of the way the prosodic operation of Strong-Weak assignment operates on sisters (i.e. the see-saw) the adjectival part appears to be stressed and focused, and the nominal part destressed and thus marked as given. But it is not necessarily the case that the function of the construction is to mark the nominal part as given and to mark the adjectival part as focused. These may diverge: as I have shown by the examples in (42)-(43) above, the function of the Greek polydefinite is to mark the nominal part as given. It is simply a by-product of the syntax of the construction and the see-saw nature of stress assignment rule that the adjective is focused. In fact, focussing and givenness marking need to be distinguished more generally. This is the subject of the next section.

8 The question mark in (45) indicates the judgment of Marika Lekakou, who finds data where both the split and the remnant DP have a definite article marginal in general. To the extent that the example is allowed, it has the contrastive reading indicated in the text. 


\section{In defense of two systems: focussing does not equal givenness marking}

\subsection{No Occam's razor when you need two systems}

Wagner $(2006,2010)$ following Schwarzschild (1998) developed a theory of marked contrastive focus as givenness marking of the sister of the focal constituent. His theory is based on the idea that the see-saw-like property of stress assignment suggests that destressing and stress strengthening is one and the same operation, and consequently focussing a constituent is the same thing as destressing its sister, and vice versa. We saw above that this is indeed true in many cases. His theory involves no duplication (an improvement on Schwarzschild's original proposal): there is only one way to ensure that a constituent is focused, i.e. by applying destressing to its sister.

In contrast, in Neeleman et al's (2009) system marked contrastive focus does not necessarily equal givenness marking of the sister of the focal constituent. Rather, following Neeleman and Reinhart's (1998) original proposal, they take destressing and stress strengthening to be separate prosodic operations.

I will now argue that this duplication is empirically necessary. This has the consequence that no Occam's razor-type arguments apply (see also Neeleman and Reinhart 1998, Neeleman and Szendröi 2004, Féry and Samek-Lodovici 2006, Krifka 2006 and Reinhart 2006). No matter how much simpler and therefore a priori more appealing a system without duplications is, if one can show that both operations are empirically necessary, then arguments of elegance and simplicity do not apply. I concede that Wagner (2010) was right about destressing triggering a see-saw. However, we still need stress strengthening as a separate operation. In contrast to destressing, stress strengthening does not trigger destressing on its sister by the see-saw.

\subsection{Marked focus can be destressing ... but it need not be}

Wagner's (2010) proposal to equate focussing and givenness marking rests on the see-saw nature of stress assignment: if a Strong label is changed to Weak in order to account for its anaphoric nature, the Weak label on its sister must automatically be changed to Strong. And conversely, a Weak label can be changed to Strong in order to account for its contrastively

focused nature, but then its sister must be marked Weak, and therefore 


\section{Kriszta Szendrői}

given. I would like to raise the question whether these two cases are in fact truly parallel, and equally motivated.

Let us take the case of destressing first. Consider the state of affairs schematically illustrated in (51a). Assume that the Node 1 undergoes anaphoric destressing because the constituent corresponding to that node is given. This node is then assigned a Weak label. This is illustrated in the second tree diagram in (51b). As (51b) shows, this leads to an impossible state of affairs. Two Weak nodes cannot be dominated by a Strong node. In theory, two possible escape routes are open. First, as shown in the third diagram in (51c), one may change the Strong label on Node 3 to Weak as well. But this would mean that the constituent corresponding to this node, Node 3, is anaphorically given, which may or may not be the case, depending on the status of the material under Node 2. But even if material under Node 2 was in fact given, then Node 3 should have been the one that was marked as given instead of Node 1 in the first place. So, this route is in fact only a theoretical possibility. The only way out of this, then is to apply the see-saw to Nodes 1 and 2, and assign a Strong label to Node 2. So, Wagner's see-saw is motivated in case anaphoric destressing targets a particular Strong-labelled node.

a.

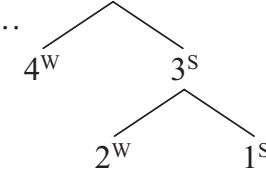

$\rightarrow \mathrm{b}$.

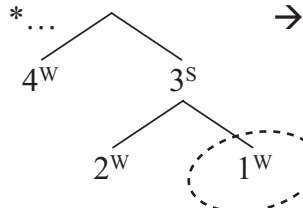

$\rightarrow c$



$\rightarrow \mathrm{d}$

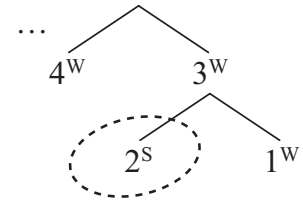

The situation does not seem to me to be quite the same with stress strengthening. Assigning a Strong label to an otherwise Weak node would create a Strong-Strong sister pair, but that is not necessarily a prosodic violation. Why should two accents be disallowed? Even if the configuration of the tree is such that the two accents end up on adjacent words, in violation of the Obligatory Contour Principle, this can be remedied on the surface, by inserting a short pause, or by downstepping one of the accents. The upshot is that unlike destressing, which seems to have automatic consequences for its sister, stress strengthening is not necessarily understood 
on a node in relation to its sister. It can be, and then the see-saw can take care of that. But it need not be.

\subsection{When it IS: givenness marking triggers the see-saw}

Consonant to Wagner's (2010) proposal, anaphoric destressing triggers the see-saw. In fact, it is potentially possible to see this example as a case of applying contrastive focus to the verb. Crucially, the domain of contrast, which is the open proposition \{My neighbour did $x$ to a desk\} is not marked explicitly in the syntax. So, Neeleman et al's (2009) proposal does not apply. Instead, Wagner's see-saw applies, ensuring that a desk is destressed and thus marked as given, while the verb is contrasted.

A: Has your neighbour bought a desk already?

a. B: \#My neighbour is building a DESK.

(Neeleman and Reinhart 1998)

b. B: My neighbour is BUILDING a desk.

In fact Wagner (2010) is correct in arguing that destressing must be allowed to apply to constituents larger than DP. ${ }^{9}$ In the following example, arguably the whole extended VP is building a desk is anaphorically given and therefore destressed. By the see-saw, this has the effect of contrasting the subject, $M Y N E I G H B O U R$.

(48) A: Last week, there was a lot of noise because Bill was building a desk. What's the noise today?

a. \# B: [F My neighbour is building a DESK].

b. B: [F MY NEIGHBOUR is building a desk]. (Wagner 2010: ex 90)

\subsection{When it is NOT}

\subsubsection{Adjective reordering as givenness marking?}

Recall from Section 1 that Wagner (2006, 2010), following Schwarzschild (1998), argued that marking a noun given by destressing automatically makes its sister focused. So, previous mention of a red convertible allows

9 The see-saw, at least in English, can also apply to domains smaller than the DP: see Wagner's examples included here as (9)-(10) above. 
subsequent occurrence of the NP a BLUE convertible with noncanonical stress placement. Wagner's point was that convertible is given in the discourse, so can be marked as Weak, so long as its sister, $B L U E$, can be understood as felicitously contrasting with the previous modifier (in this case red). So, the adjective BLUE bears Strong by what I called the seesaw rule of prosodic stress assignment. In this section I would like to show that his theory cannot explain the adjective reordering data discussed above.

Recall also our example from Section 2, repeated here for convenience:

I drive a BLACK big car. Context 1: $\checkmark \quad$ Context 2: \#

a. Context 1: In this car park you can see my friends' cars and my car. There is a bunch of big cars here. There are many different colours.

Scenario 1: BLACK RED BLUE WHITE BLUE YELLOW

b. Context 2: In this car park you can see my friends' cars and my car. There are cars of many different colours. Some of them are small, but there are big cars of every colour.

Scenario 2: black BLACK black black

red red red $R E D$ red red

Under Wagner's (2010) proposal: (15) is predicted to be appropriate if the NP big car was given in the previous discourse and the adjective black contrasts felicitously, i.e. if big cars of various colours are available in the context. This is in fact true in both contexts. The difference between the contexts lies in whether BLACK applies to a set of cars or a set of big cars; in the domain of contrast. So, Wagner's theory fails to capture the fact that (15) is only felicitous in Context 1 , but not in Context 2 . It is too permissive. So, it would have to be supplemented by something along the lines of the present proposal, namely, with the idea that the domain of contrast is not determined by the prosodic see-saw, but by A-bar movement.

\subsubsection{Postfocal but not given}

In other cases, Wagner's theory is too restrictive. His see-saw operation makes the sister of every Weak-marked constituent Strong and conversely, the sister of any constituent receiving a marked Strong label, will automatically receive Weak, by the see-saw. This predicts that the sister of a 
moved and focused constituent, which bears Strong by assumption, will be marked as Weak, and will therefore be interpreted as anaphorically given. So, he predicts that the material on the right of the moved adjective should be destressed. But, as the following examples (from Ad Neeleman and Reiko Vermeulen p. c.) illustrate, this is not necessarily the case. (46) allows adjective fronting inside the DP even though the noun BUS is not anaphorically destressed. (47) shows that the movement, as in (15), is optional.

(46) I'd really like a big car. But a RED big BUS would be fine too.

(47) I'd really like a big car. But a big RED BUS would be fine too.

But, Neeleman et al's (2009) proposal gives the right prediction. In (46), the domain of contrast for RED is the set of big buses. This is the scope of the moved element. In terms of accenting, the DP bears two accents, arguably both contrastive. So, Wagner's (2010) predictions do not hold. This time, it undergenerates.

There are, in fact, many cases where the postfocal domain is not given or fully destressed. Take for instance Neeleman and Reinhart (1998)'s example in (48), which involves focusing on the noun milieu-fanaat 'environmental fanatic' in the scope of zelfs 'even' even though the NP een auto 'a car' is not destressed. To obtain marked stress on the former, while retaining the original accent on the latter, an independent stress strengthening operation is necessary. The see-saw rule would not work.

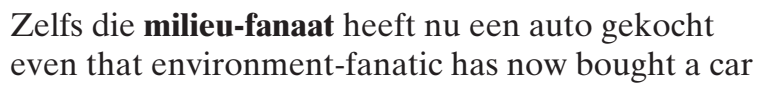

(Neeleman and Reinhart 1998, ex. 61)

There are also such cases in English. A few random examples from the British National Corpus (my caps) illustrate the same point. In (49) two is stressed and focused, while eyes need not be given or destressed. Further, the contrast on above and below licences focal stress while water surface need not be given or anaphorically destressed. In (50) stress and focus is required on nomadic and tribal but the discussion could be about pigments in which case rugs need not be previously mentioned or anaphorically destressed.

(49) It only has TWO eyes but they are divided for viewing ABOVE and BELOW the water surface. 
Strong or dark shades are normally only found in NOMADIC and TRIBAL rugs.

So, cases involving postfocal but not given material seem to be systematically available and cannot be argued to be sporadic.

\subsubsection{Icelandic}

Wagner's unified proposal predicts that if a language or construction lacks anaphoric destressing it should disallow stress strengthening too. ${ }^{10}$ This is because these are two sides of one and the same prosodic operation, a Strong-Weak swap. Italian is a case in point: generally, it allows neither anaphoric destressing nor stress strengthening. But as Dehé (2009:20-21 ex. 18) reports, Icelandic has obligatory stress strengthening but only optional anaphoric destressing. To illustrate, she elicited utterances with various focal patterns determined by a preceding question. She found that the focal element always bore a pitch accent; so Icelandic seems to be similar to English when it comes to focussing.

a. (Q: Hverjum gaf Stéfan appelsínuna? 'To whom did Stéfan give the orange?')

A: Stéfan gaf [Elínu $]_{\text {Foc }}$ appelsínuna.

Stéfan gave Elín orange.DEF

'Stéfan gave the orange to Elín.'

b. (Q: Hverjum sendi Björg bæklinginn? 'To whom did Björg send the booklet?')

A: Björg sendi [Elínu $]_{\text {Foc }}$ bæklinginn.

Björg sent Elín booklet.DEF

'Björg sent the booklet to Elín.'

c. (Q: Hverjum gaf Hildur eplið? 'To whom did Hildur give the apple?')

A: Hildur gave [Ástu $]_{\mathrm{Foc}}$ eplið.

Hildur gave Ásta apple.DEF

'Hildur gave the apple to Ásta.'

10 In fact, Wagner also predicts that there should not be a language (or a construction) where destressing is possible but stress strengthening is not. As far as I can tell, this seems correct: I know of no language that has anaphoric destressing but no stress shift for focus. 
But as she reports, although all speakers accented the focal indirect object in all cases, 'of the five speakers, three speakers failed to deaccent the direct object (DO) appelsinuna in (52a), two speakers failed to deaccent the DO baeklinginn in (52b), and two speakers failed to deaccent the DO eplið in (52c). In this data set, all post-focus pitch accents were of the same type as the focus-marking pitch accent and were downstepped with respect to the focus-marking pitch accent.' (Dehé 2010:20-21). An instance of an utterance involving the material in (52c) with no deaccenting is given in Figure 1. (Dehé refers to Nolan \& Jónsdóttir (2001) for corroborating the findings about the lack of deaccenting.)

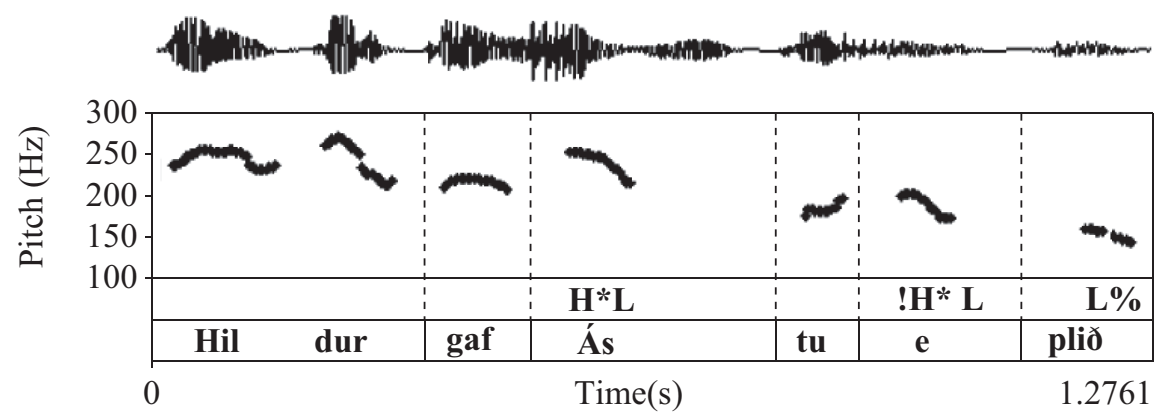

Figure 1: Accenting of contextually given information: given information eplið (see (52c)) fails to be deaccented by a (female) speaker. (from Dehé 2010:21)

So, Icalandic seems to go agianst the purported generalisation of Wagner (2010) that languages that apply marked prosodic operations for focussing also apply deaccenting. In Icelandic, stress shift for focussing seems to be obligatory, while deaccenting given material seems to be optional.

\subsubsection{Language acquisition}

Arguably, a similar pattern emerges in language acquisition. It has been found in different experiments that typically developing children always stress focal constituents, but sometimes fail to destress given ones (see e.g. Baltaxe 1984, Chen 2010). Children with certain pathologies such as autism seem to show the effect in a more marked way (Baltaxe 1984). This is in line with the idea that destressing and stress strengthening are two 
different operations. Children seem to use stress strengthening correctly earlier than they reliably use anaphoric destressing. ${ }^{11}$

I would like to conclude then, that in the light of this evidence it is perhaps not so problematic to have in our grammar both a stress strengthening and a destressing operation. It would not be a straight forward duplication, but rather, two operations with overlapping and sometimes not identical effects.

\subsection{Superman rules}

Wagner (2010:35-44) discusses extensively why Reinhartian approaches to stress shift and deaccenting are wrong. In particular, he discusses and re-analyses in his local alternatives approach so-called 'Superman' sentences put forward by Neeleman and Szendröi (2004) in defense of stress strengthening. I would like to reproduce his arguments against Neeleman and Szendröi's (2004) position and counter them. I will try to show that contrary to his claim, Wagner's local alternatives approach cannot handle Superman sentences, so stress strengthening is still necessary to account for them.

As I already discussed in section 4.3 Wagner (2010) argues that the contrast in (53) vs. (54) suggests that (53) involves anaphoric destressing, based on the presence of the VP was building a desk in the preceding context. This is because contrastive stress on the subject DP MY NEIGH$B O U R$ is only felicitous if the VP is building a desk is explicitly and accessibly given in the previous context.

A: Last week, there was a lot of noise because Bill was building a desk. What's the noise today?

a. \# B: $\left[{ }_{F}\right.$ My neighbour is building a DESK].

b. B: $\left[{ }_{F}\right.$ MY NEIGHBOUR is building a desk]. (Wagner 2010: ex 90)

(54) A: Last week, Bill was visiting. What's going on this week?

B: \# [F MY NEIGHBOUR is building a desk]. (Wagner 2010: ex 93)

11 It is of course a possibility that there is an independent reason why children (especially autistic children) would have a problem applying destressing even though the same grammatical operation derives focussing and deaccenting. For instance, it could be that the pragmatic import of deaccenting, i.e. anaphoric givenness, is something they apply reliable only at an older age. I will have to leave this possibility open here. 
Indeed, this contrast convincingly shows that anaphoric destressing must be allowed to apply to constituents larger than lexical items.

Wagner (2010) offers a reanalysis of Neeleman and Szendrői's (2004) Superman sentences in terms of anaphoric destressing. This is necessary in his approach, which does not make a difference between stress strengthening and destressing. Let us retell the original argument here. Neeleman and Szendröi (2004) presented an utterance with complex, nested focus. Arguably, the context provided ensures that the utterance in (55), with prosodic prominence on the direct object Superman, involves contrastive focus on the direct object, contrasting it with 'decent books', the VP reading Superman to some kid, contrasting it with 'doing his homework'. Furthermore, the whole utterance answers the context question 'What happened?', so it also involves focus on the whole sentence.

Suppose father comes home from work and finds mother in obvious distress. Then the following discourse may take place:

Father: What happened?

Mother: You know how I think our children should read decent books. Well, when I came home, rather than doing his homework, [IP Johnny was [VP reading [DP SUPERMAN] to some kid].

Wagner (2010:40) claims that in his local alternatives approach he 'could analyze this example as having the constituent 'read $x$ to some kid' being marked as given relative to the 'Superman." As he acknowledges in a footnote, this would also require some nontrivial syntactic movements to take place as Superman is not actually the sister of 'read $x$ to some kid'. But this is a technical problem. More importantly, the constituent 'read $x$ to some kid' is not given in the context. Neeleman and Szendröi (2004) designed the context with the specific aim in mind that it would not be. So, Wagner has to assume that it is accommodatable. He says that this is plausible based on (56), where, he claims ' $x$ made the best seller list' is also accommodated.

(56) Context borrows the negative view of Superman comics from the original example:

Father: What happened?

Mother: I thought good fiction is valued in the country. Well, I just read that A SUPERMAN comic made the best seller list.

(Wagner 2010: ex 94) 
But what makes ' $x$ made the best seller list' accessible when the context mentions that good fiction is valued in the country? Or what makes 'read $x$ to some kid' accessible in a context where Johnny was expected to do his homework? Importantly, Wagner has to answer these questions with a proposal about accommodation that is not too powerful: he has to make sure that whatever forces are at work in (55) and (56), they are not applicable to (54). In other words, he has to make sure that 'is building a desk' does not become accessible in the context given in (54) mentioning Bill's previous visit. Without such a theory of accommodation, the contrast between (55) and (56) on the one hand and (54) on the other is not actually explained, merely noted.

In my view, we may explain this contrast in a theory with two operations: (54) is inappropriate because anaphoric destressing cannot apply unless the destressed constituent is given, as Wagner himself proposed. (56) is indeed parallel to (55). It involves stress strengthening and complex (nested) focus; it is a 'Superman' sentence. Thus, no accommodation needs to be assumed. In particular, in (56) the subject a Superman comic contrasts with good fiction and the entire sentence A Superman comic made the best seller list contrasts with the previous utterance Good fiction is valued in this country.

The question that we now face is why an example like (54) cannot involve stress strengthening and complex focus. In other words, how do we turn (54) into a Superman sentence? To see this let us first dissect the original Superman sentence in (55). As I have already claimed, it is a crucial part of the example that the indirect object, following the direct object, is not given. It is also important, however, that the indirect object is not itself contrasted. If it was, there would be two accents: one on the direct object and one on the indirect object. Witness (57), from Neeleman and Szendröi (2004), where the context invited contrast on both the direct object and the indirect object, in addition to the contrast on the VP (and the additional focus on the IP).

\footnotetext{
You know how I want our children to read decent books and how I think it is important that Johnny plays with kids his own age. Well, when I came home, rather than doing his homework, [IP Johnny was [VP reading [DPSUPERMAN] to [DP SOME SIXTEEN-YEAR OLD]]]. (Neeleman and Szendröi 2004:153, ex 12)
}

This is why an indefinite like to some kid is ideal as an indirect object in a Superman sentence. Thus, in order to turn (54) into a Superman sentence, we need to make sure that there is a contrast on the subject DP my neigh- 
bour, and on the entire sentence, but, crucially, not on the VP following the subject. The VP also cannot be given. Wagner's example (56) achieves precisely that. In (56), the subject a Superman comic contrasts with good fiction and the entire sentence $A$ Superman comic made the best seller list contrasts with the utterance Good fiction is valued in this country. At the same time, the two VPs, made the best seller list and is valued in this country do not contrast. This is why a unique accent on the subject is so easily available. In order to turn (54) into a Superman sentence, we need to do the same thing. However, this means that we would have to find a context where my neighbour is contrasted with some other DP, the utterance My neighbour is building a desk is contrasted with some previous utterance, while the VP is building a desk is neither contrasted nor given. The examples I created, in (58), involves some changes compared to (54) because I found it hard to include a VP is building a desk without it being either given or contrastive. In (58) there is a contrast on the subject my neighbour with other people who are not so close to the speaker. There is also a contrast between My neighbour is buying a car and the context sentence 'I thought that people in this ecovillage were environmentally conscious.' The latter contrast expresses the speaker's dismay at his situation. This example is not as neat as Wagner's (56) in that here the VP 'is buying a car' could be contrasted with 'were environmentally conscious' but apparently it is not necessary to do that, so main stress on the subject is permissible. Note that there is a secondary stress on the object 'a car', but that is simply due to the fact that it is a nonspecific indefinite. The focus "projects" from the accent on the subject.

$$
\begin{aligned}
& \text { A: I thought people in this ecovillage were environmentally conscious. } \\
& \text { But things have been getting worse and worse ... } \\
& \text { Now [ }{ }_{F} \text { MY NEIGHBOUR is buying a car]! }
\end{aligned}
$$

Another example showing the same phenomenon is in (59). Here the expectation is built up in the context that the place is not as socialist as it used to be. Again, a contrast is built up between my neighbour and other people living further away. What upsets the speaker is that his neighbour is becoming individualistic. Here, perhaps it is less obvious how the VP 'is building a fence' would directly contrast with any of the predicates mentioned in the context. Again, the focus responsible for contrasting the whole proposition "projects" from the main prominence on the subject. The secondary stress on the object is just to mark the DP 'a car' as nongiven. 
A: People in this kibbutz used to live in a real socialist community: everything we owned would be shared by everyone. Over the last couple of years, some more materially conscious people moved in. I didn't like that, but I also didn't care that much. But now ${ }_{\mathrm{F}} \mathrm{MY}$ NEXT DOOR NEIGHBOUR is building a fence]!

\section{Focussing and givenness: a complete typology at the clause-level and inside the DP}

Let us take stock. I reviewed both some syntactic and some prosodic options avilable in the grammar to ensure that a particular element is focused or marked as given. In this paper, I concentrated on how these operations apply inside the DP. In particular, I showed that adjective reordering involves A-bar movement marking the domain of contrast in the sense of Neeleman et al (2009). In contrast, the Greek polydefinite instantiates anaphoric destressing. It does not involve A-bar movement, and consequently does not serve to mark the domain of contrast. Destressing triggers Wagner's (2010) see-saw and may apply at various structural levels. A separate prosodic operation, stress strengthening is necessary to account for instances of multiple focus and postfocal nongiven material. I showed that this operation is also necessary to account for Neeleman and Szendröi's (2004) 'Superman' sentences and for those Icelandic speakers that allow focus strengthening in the absence of anaphoric deaccenting. This operation does not obligatorily trigger the see-saw effect. Stress strengthening may also apply in the nominal domain, as illustrated above by sentences such as the English example I'd really like a big car. But a RED big BUS would be fine too. Here, two accents occur inside the subject DP: presumably, the accent on $B U S$ would be assigned by the nuclear stress rule and the stress on $R E D$ by stress strengthening.

Having seen that givenness can be marked by deaccenting, we may ask whether there is a syntactic option available in language whose function is to mark anaphoric givenness. In the present proposal, which follows Neeleman et al (2009) in assuming that A-bar movement associated with with focusing serves to mark the domain of contrast, we do not expect that givenness marking would be associated with A-bar movement. If givenness marking does not have the same quantificational, scope-taking properties as A-bar movement associated with focussing does, then no movement marking the domain of contrast should be associated with it. At same time, arguably, A-scrambling in languages like Dutch and German seems to mark givenness. As Neeleman and Reinhart (1998) and Neele- 
man and Van de Koot (2007) and many others have argued, the import of A-scrambling is that it allows a DP to be merged in a position where it would not receive main stress, and consequently focal interpretation, by the nuclear stress rule. So, apart from anaphoric destressing, a further way to mark a DP as given is by A-scrambling. ${ }^{12}$

Given the logic of Wagner's proposal, in contrast with prosodic destressing, A-scrambling is not expected to have an automatic stress strengthening effect. Rather, main stress assigned by the nuclear stress rule will simply fall on another constituent. No marked prosodic operation (i.e. Weak-Strong swap) takes place, so there should be no requirement that the constituent that bears main stress be interpreted contrastively with respect to a previous mention. This seems to be true. (60) involves Dutch data from Neeleman and Reinhart (1998: 343, ex 79, 81) involving object scrambling across an adverb. Here, the nuclear stress rule assigns main stress to the verb, but as the focal possibilities indicate, this need not be contrastive focus on the verb itself.
a. dat Jan het boek gisteren gelézen heeft that John the book yesterday read has Scrambled structure
b. Focus set: $\{\mathbf{I P}, \mathbf{V P}, \mathbf{V}\}$
c. Object: Destressed

Similarly, in German, a direct object may scramble across a dative object as in (62), with main stress now falling on the indirect object. Scrambling destresses the direct object (cf. (61) with (62)), but it does not automatically focus the indirect object. Rather, the focus can project from the neutral stress position to the VP or the whole IP. (German data from B. Gehrke p.c.)

a. Kai sagte, dass Verena ihrer Mutter die BrombeERE Kai said that Verena her mother.DAT the blackberry. ACC geben würde give would 'Kai said that Verena would give the blackberries to her mother.'

b. Focus set: $\{$ IP, VP, DPacc $\}$

12 Another candidate for syntactic givenness marking is left- and especially right-dislocation in Romance languages (Szendrői (2002:297-300), DelaisRoussarie et al. (2004:528), Astruc (2005), Feldhausen 2010: ch.5). I leave this issue open here. 
a. Kai sagte, dass Verena die Brombeere ihrer Kai said that Verena the blackberry.ACC her MutTer geben würde mother.DAT give would

'Kai said that Verena would give the blackberries to her mother.'

b. Focus set: $\{\mathbf{I P}, \mathbf{V P}$, DPdat $\}$

c. Direct Object: Destressed

Interestingly, as (63) shows, if the scrambled direct object is a nonspecific indefinite, and thus the trigger for scrambling may not be its need to be destressed, the indirect object must bear narrow focus. This would be a case of focus-induced scrambling in the sense that the function of the scrambling is not destressing the scrambled object, but focusing the constituent that scrambling crosses. ${ }^{13}$
a. dass Verena eine
Brombeere
ihrer MutTer gegeben hat that Verena a blackberry.acc her mother.dat given
b. Focus set: $\{$ DPdat $\}$

Although they did not discuss such cases, Neeleman and Reinhart's (1998) economy principles could perhaps be evoked to account for the obligatory narrow reading: since scrambling does not serve the function of deaccenting the direct object it must have some other interpretative consequence, such as narrow focus on the indirect object. It is not clear how the contrast between (62) and (63) could be explained in a theory, such as Wagner's, which does not distinguish focussing from givenness marking.

The final issue to be considered then is whether there are also cases of A-scrambling DP-internally. In other words, whether noncanonical orders in the DP are sometimes licensed by the need to mark a subpart of the DP as given. Although I cannot offer a full account of these cases, I would like to suggest that an example by (Simik and Wierzba 2012) instantiates this option in Czech. In (64), the noun can optionally undergo DP-internal reordering to the left in order to avoid stress.

13 Note that (63) is of course also grammatical with contrastive focus on the indefinite accusative object, but in that case it would constitute a case of A-bar scrambling and thus focussing, and marking of the domain of contrast for the accusative object. 
(64) What kind of fish do you like?
a. Jím predevším [DP MOŘSKÉ ryby] eat:1sg mainly sea fish
b. Jím především [DP ryby MOŘSKÉ]
eat:1sg mainly fish sea

To conclude, I argued that we need to distinguish focus marking from givenness marking, challenging Wagner's (2010) unified proposal. Thus we arrive at a four-way typology: the syntactic ones are A-bar movement for focussing and A-scrambling for givenness marking and the prosodic ones are stress strengthening and destressing. It seems that all of these options can be instantiated at the clausal level as well as inside the noun phrase. 